\title{
KESESUAIAN DIAGNOSIS PADA BERKAS REKAM MEDIS DAN EHR PASIEN INSTALASI GAWAT DARURAT
}

\author{
Danik Lestari ${ }^{1}$, Nuryati ${ }^{2}$ \\ 1,2 Rekam Medis Sekolah Vokasi Universitas Gadjah Mada \\ Email: daniqq_27@yahoo.co.id, nur3yati@yahoo.com
}

\begin{abstract}
The purpose of this study is to determine the extent to which the suitability of documenting the diagnosis on the patients' file of medical record Emergency Unit with the EHR. The type of this research is descriptive study with a qualitative approach. The population in this study are 2837 patients' file of medical record Emergency Unit in RSA UGM in 2013 year and 15 doctors of Emergency Unit. The most used sample was 100 Emergency sheet forms on a data file 100 clinical manuals and documentation in the EHR. The results of this study indicates diagnosis writing between medical record file with the appropriate EHR as much as $89 \%$ and that does not suitable as much as $11 \%$. The causes of diagnosis of nonconformities writing medical record file with the EHR are 1, no special rules governing about writing the diagnosis in the medical record file and EHR, 2. the doctor must write the diagnosis twice, 3. Writing the diagnosis in two documents (files and medical record EHR) are ineffective, 4 the term diagnosis of EHR and the term of diagnosis of ICD-10 diagnosis are difficult to equate.
\end{abstract}

Keywords: EHR (Electronic Health Record), Suitable diagnosis, Emergency Unit patients file medical record.

\begin{abstract}
Abstrak
Tujuan penelitian ini adalah untuk mengetahui sejauh mana kesesuaian pendokumentasian diagnosis pada berkas rekam medis pasien Instalasi Gawat Darurat dengan EHR.Jenis penelitian ini adalah penelitian deskriptif dengan pendekatan kualitatif. Populasi dalam penelitian ini adalah 2837 berkas rekam medis pasien IGD di RSA UGM tahun 2013 dan dokter IGD berjumlah 15 orang. Besar sampel yang digunakan adalah 100 lembaran formulir Gawat darurat pada berkas manual dan 100 data clinical documentation pada EHR. Hasil penelitian ini menunjukkan Penulisan diagnosis antara berkas rekam medis dengan EHR yang sesuai sebanyak $89 \%$ dan yang tidak sesuai sebanyak $11 \%$. Dan penyebab ketidaksesuaian penulisan diagnosis berkas rekam medis dengan EHR adalah 1. belum ada peraturan khusus yang mengatur tentang penulisan diagnosis pada berkas rekam medis dan EHR, 2. dokter harus menulis diagnosis dua kali, 3. Penulisan diagnosis pada dua dokumen (berkas rekam medis dan EHR) tidak efektif, 4. Istilah diagnosis pada EHR dan istilah diagnosis pada ICD-10 sulit disamakan.
\end{abstract}

Kata Kunci: EHR (Electronic Health Record), Kesesuaian diagnosis, pasien IGD, berkas rekam medis.

\section{PENDAHULUAN}

Sebagai salah satu fasilitas pelayanan kesehatan yang menyeluruh rumah sakit berkewajiban memberikan pelayanan kesehatan sesuai dengan pokok sasarannya masing-masing. Selain itu, rumah sakit juga berkewajiban untuk menyelenggarakan pembuatan dan pemeliharaan rekam medis. Sehingga segala bentuk pengobatan dan tindakan yang diberikan kepada pasien harus didokumentasikan dengan baik ke dalam rekam medis.
Secara umum rekam medis berisi data administrasi dan data klinis. Data administrasi berisi data-data sosial pasien, sedangkan data klinis berisi data yang berkaitan dengan keadaan klinis pasien. Data-data tersebut yang nantinya akan diolah oleh tenaga perekam medis menjadi sebuah informasi yang berguna bagi pihak-pihak yang bersangkutan. Informasi tersebut tentunya akan berguna apabila data-data yang terkandung di dalamnya benar-benar dapat memberikan arti. Oleh karena itu, proses pendokumentasian data-data pasien ke dalam rekam 
medis harus dilakukan dengan benar dan tepat. Untuk itu tenaga perekam medis mempunyai kewajiban untuk menjaga mutu rekam medis termasuk kualitas data-data tersebut sesuai dengan Peraturan Menteri Kesehatan Republik Indonesia Nomor 377/Menkes/ SK/III/2007 Tentang Standar Profesi Perekam Medis Dan Informasi Kesehatan yang didalamnya menyebutkan bahwa perekam medis melaksanakan program kegiatan menjaga mutu (QA) rekam medis. Pelaksanaan kegiatan menjaga mutu rekam medis (QA) dapat dilakukan dengan analisis kuantitatif maupun analisis kualitatif pada berkas rekam medis baik yang berbentuk manual ataupun elektronik. Salah satunya adalah yang berkaitan dengan pendokumentasian data-data pasien pada rekam medis berbentuk kertas maupun rekam medis yang berbentuk elektronik Salah satu data pasien yang penting dan harus didokumentasikan dalam rekam medis adalah data diagnosis. Hal ini diperjelas dalam Peraturan Menteri Kesehatan Rebuplik Indonesia Nomor 269/MENKES/PER/III/2008 tentang Rekam Medis bahwa isi rekam medis untuk pasien rawat jalan, rawat inap, dan gawat darurat sekurangkurangnya memuat identitas pasien, tanggal dan waktu, hasil anamnesis, hasil pemeriksaan fisik dan diagnosis. Data diagnosis pasien tersebut merupakan data yang penting karena data diagnosis digunakan untuk memastikan penyakit yang diderita seseorang, berkaitan dengan penanganan yang akan diberikan dokter serta berkaitan erat dengan komplikasi yang mungkin saja dapat terjadi. Selain itu, data diagnosis merupakan salah satu komponen yang ditelaah dalam pelaksanaan analisis kualitatif berkas rekam medis dalam hal kejelasan dan konsistensi. Dengan demikian data diagnosis pasien harus didokumentasikan dengan benar dan sesuai, baik pada rekam medis manual maupun rekam medis elektronik. Sehingga memudahkan proses analisis terhadap isi masukan oleh tenaga kesehatan dan kegiatan yang berkaitan dengan menjaga mutu rekam medis (QA) yang dilakukan pada rekam medis dalam bentuk kertas ataupun dalam bentuk elektronik (EHR).

\section{HASIL DAN PEMBAHASAN}

a) Kesesuaian diagnosis pada berkas rekam medis dan EHR Pasien IGD di RS Akademik UGM Yogyakarta
Tabel. 6 hasil analisis kesesuaian penulisan diagnosis antara berkas rekam medis dengan EHR pasien IGD

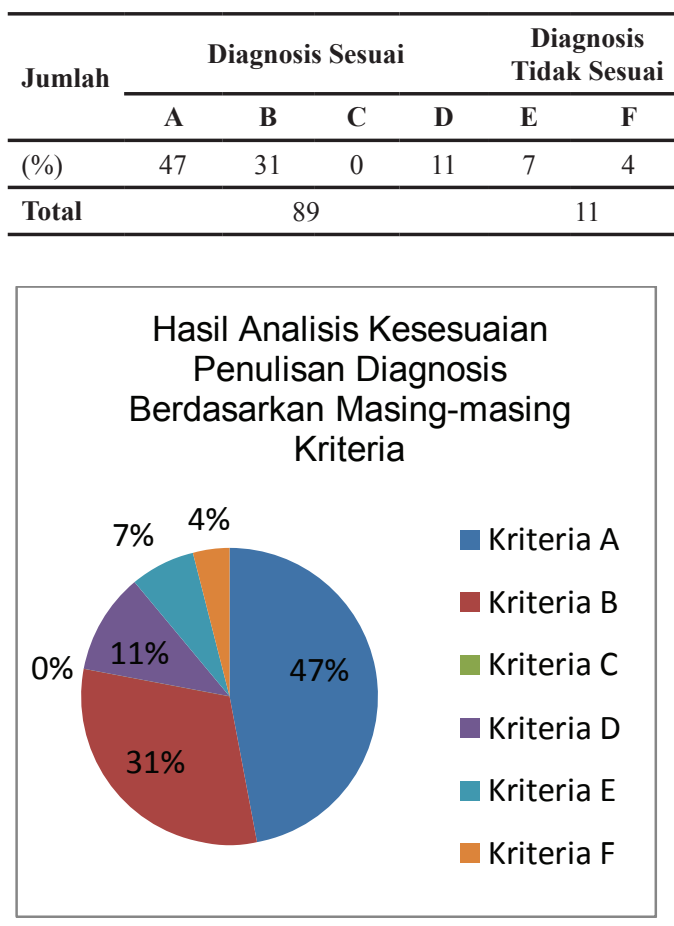

Grafik.1 Hasil Analisis Kesesuaian Penulisan Diagnosis MasingMasing Kriteria

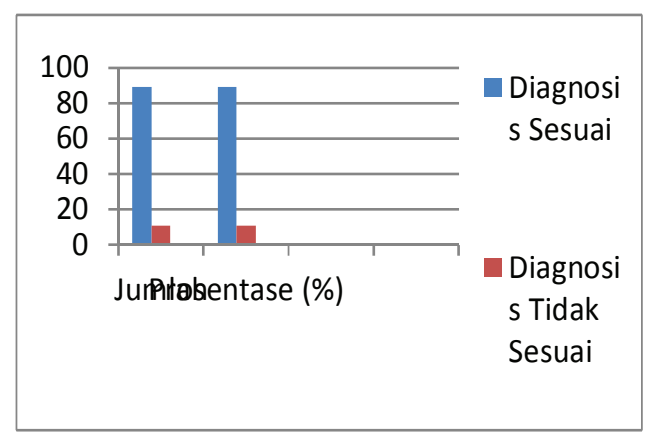

Grafik.2 Hasil Analisis Kesesuaian Penulisan Diagnosis Antara Berkas Rekam Medis Pasien IGD dan EHR

Dari tabel. 6, diagram lingkaran pada grafik.1 dan diagram batang pada grafik.2 diatas dapat diketahui bahwa hasil kesesuaian penulisan diagnosis antara berkas rekam medis dengan EHR pasien IGD terdiri dari dua komponen yang masing-masing memiliki kriteria yang berbeda. Komponen yang pertama adalah penulisan diagnosis sesuai yang terdiri dari kriteria A yaitu : Tulisannya sama persis, keduanya menggunakan bahasa sesuai terminologi medis, 
dan artinya sama, kriteria B yaitu : Tulisan beda, keduanya menggunakan bahasa sesuai terminologi medis dan artinya sama, kriteria $\mathrm{C}$ yaitu : Tulisan beda, satu ditulis menggunakan bahasa sesuai terminologi medis tetapi yang satu tidak dan artinya sama dan kriteria yang terakhir adalah kriteria D yaitu : Tulisan beda, satu ditulis menggunakan singkatan dan yang satu tidak dan artinya sama. Kemudian komponen yang kedua adalah penulisan diagnosis tidak sesuai yang terdiri dari kriteria E yaitu : Tulisan beda, keduanya menggunakan bahasa sesuai terminologi medis dan artinya beda, dan kriteria F yaitu: Tulisan beda, satu ditulis menggunakan bahasa sesuai terminologi medis tetapi yang satu tidak dan artinya beda.

Dari persentase pada tabel.6 diatas dapat diketahui bahwa persentase penulisan diagnosis sesuai yaitu diagnosis yang ditulis pada berkas rekam medis sama persis dengan yang ditulis pada EHR dan artinya pun sama sebesar 47 $\%$ yang terdiri dari kriteia A sebesar $47 \%$, diagnosis yang ditulis pada berkas rekam medis penulisannya berbeda dengan yang ditulis pada EHR, keduanya menggunakan bahasa sesuai terminologi medis dan artinya sama atau satu ditulis menggunakan bahasa sesuai terminologi medis tetapi yang satu tidak dan artinya sama atau satu ditulis menggunakan singkatan dan yang satu tidak dan artinya sama sebesar $42 \%$ yang terdiri dari kriteria B sebesar $31 \%$, kriteria $\mathrm{C}$ sebesar $0 \%$ dan kriteria D sebesar $11 \%$. Dan yang terakhir adalah persentase penulisan diagnosis tidak sesuai yaitu diagnosis yang ditulis pada berkas rekam medis penulisannya berbeda dengan yang ditulis pada EHR, keduanya menggunakan bahasa sesuai terminologi medis dan artinya berbeda, atau satu ditulis menggunakan bahasa sesuai terminologi medis tetapi yang satu tidak dan artinya berbeda sebesar $11 \%$ yang terdiri dari kriteria E sebesar $7 \%$ dan $\mathrm{F}$ sebesar $4 \%$.

Dengan demikian dapat dikatakan bahwa persentase kesesuaian penulisan diagnosis sesuai lebih tinggi dari pada penulisan diagnosis tidak sesuai. Dengan selisih yang cukup besar yaitu sebesar $78 \%$. Persentase masing-masing kriteria yang paling tinggi adalah pada kriteria A yaitu diagnosis yang ditulis pada berkas rekam medis sama persis dengan yang ditulis pada EHR dan artinya pun sama sebesar $47 \%$.
Sedangkan untuk kriteria yang mempunyai persentase paling rendah adalah kriteria $C$ yaitu Tulisan beda, satu ditulis menggunakan bahasa sesuai terminologi medis tetapi yang satu tidak dan artinya sama sebesar $0 \%$.

Menurut penelitian yang dilakukan oleh Riskawati, dkk (2011), tentang Analisis Penulisan Diagnosis Pada Lembar Ringkasan Riwayat Penyakit Pasien Rawat Inap Pasien Bedah Triwulan 1 Tahun 2011 Berdasarkan Terminologi Medis di RSUD Karanganyar berdasarkan survey pendahuluan, terdapat $70 \%$ dokumen rekam medis khususnya pada lembar Ringkasan Riwayat Penyakit Rawat Inap pasien bedah yang penulisan diagnosisnya tidak sesuai dengan penulisan dalam terminologi medis. Setelah dilakukan penelitian mendapatkan hasil yaitu penulisan istilah yang telah sesuai dengan terminologi medis sejumlah $75,33 \%$, sedangkan istilah yang tidak sesuai sejumlah $24,67 \%$. Singkatan yang sesuai dengan terminologi medis sejumlah $40,63 \%$, sedangkan singkatan yang tidak sesuai sejumlah $59,37 \%$. Penulisan diagnosis dengan istilah medis atau terminologi medis tujuannya adalah keseragaman agar istilah yang dituliskan dapat dipahami antar tenaga kesehatan.

Berdasarkan hasil penelitian yang telah diuraikan sebelumnya dapat dilihat pada tabel.6 bahwa hasil analisis penulisan diagnosis antara berkas rekam medis dengan EHR pasien IGD masih terdapat penulisan diagnosis yang tidak sesuai pada kedua dokumen tersebut sebesar $42 \%$ bahkan ada penulisan diagnosis pada kedua dokumen tersebut yang benar-benar berbeda yaitu sebesar $11 \%$. Ketidaksesuaian penulisan diagnosis tentunya akan memberikan dampak yang berarti bagi pelayanan kesehatan pasien baik yang bersifat medis maupun administrasi. Pendokumentasian dan penulisan diagnosis pada berkas rekam medis maupun EHR merupakan hal yang sangat penting mengingat diagnosis adalah salah satu data pasien yang sangat krusial yang menentukan proses pengobatan pasien selanjutnya. Untuk itu penulisan diagnosis antara kedua dokumen (berkas rekam medis dan EHR) harus sesuai dan sama persis agar tidak terjadi kesalahan penafsiran oleh pembaca dan akhirnya mempengaruhi keakuratan data klinis pasien yang akan berakibat fatal. Selain itu, penulisan diagnosis antara berkas rekam 
medis dengan EHR harus sesuai karena akan mempengaruhi kualitas dan mutu pelayanan kesehatan yang diberikan oleh rumah sakit terhadap pasien serta mempengaruhi proses pengambilan kebijakan oleh rumah sakit.

b) Fakor Penyebab dan Dampak ketidaksesuaian penulisan diagnosis pasien antara berkas rekam medis dengan EHR pasien Instalasi Gawat Darurat

1. Faktor Penyebab

Faktor penyebab ketidaksesuaian penulisan diagnosis pasien antara berkas rekam medis dengan EHR pasien Instalasi Gawat Darurat di RSA UGM Yogyakarta secara garis besar dapat dikelompokkan menjadi 2 unsur $\mathrm{M}$ dari unsur 5M.

a. Methode : Belum ada peraturan khusus yang mengatur tentang penulisan diagnosis pada berkas rekam medis dan EHR, Dokter harus menulis diagnosis dua kali pada berkas rekam medis dan EHR, dan Penulisandiagnosis pada dua dokumen ( berkas rekam medis dan EHR ) tidak efektif.

b. Materials : Istilah diagnosis pada EHR dan istilah diagnosis pada ICD-10 tidak sama.

2. Dampak

a. Mempengaruhi proses coding

b. Mempengaruhi proses pengobatan pasien

c. Mempengaruhi proses pembuatan Visum Et Repertum

d. Mempengaruhi hasil laporan morbiditas dan mortalitas Rumah Sakit

c) Upaya yang dilakukan untuk menjamin pendokumentasian diagnosis pada kedua dokumen (berkas rekam medis dan EHR) tersebut sesuai

a. Dokter mengecek langsung penulisan diagnosis antara berkas rekam medis dengan EHR

b. Petugas rekam medis melakukan pengecekan penulisan diagnosis antara berkas rekam medis dengan EHR

c. Instalasi Rekam Medis mengadakan sosialisasi maupun himbauan kepada para dokter IGD

\section{SIMPULAN}

Persentase kesesuaian penulisan diagnosis antara berkas rekam medis dengan EHR pasien Instalasi Gawat Darurat sebesar 89 \%. Faktor penyebab ketidaksesuaian penulisan diagnosis pasien antara rekam medis manual dengan EHR pasien Instalasi Gawat Darurat secara garis besar adalah pada unsur :

1). Method (Metode) yaitu belum ada peraturan khusus yang mengatur tentang penulisan diagnosis pada berkas rekam medis dan EHR, dokter harus menulis diagnosis dua kali dan Penulisan diagnosis pada dua dokumen ( berkas rekam medis dan EHR ) tidak efektif.

2). Materials yaitu Istilah diagnosis pada EHR dan istilah diagnosis pada ICD-10 tidak sama.

Dampak ketidaksesuaian penulisan diagnosis pasien antara rekam medis manual dengan EHR pasien Instalasi Gawat Darurat yaitu mempengaruhi proses coding, mempengaruhi proses pengobatan pasien, mempengaruhi proses pembuatan Visum, mempengaruhi hasil laporan morbiditas dan mortalitas Rumah Sakit dan mempengaruhi budgeting finance Rumah Sakit

Upaya yang dilakukan untuk menjamin pendokumentasian diagnosis pada kedua dokumen (berkas rekam medis dan EHR) tersebut sesuai yaitu dokter mengecek langsung penulisan diagnosis antara berkas dengan EHR, petugas rekam medis melakukan pengecekan penulisan diagnosis antara berkas rekam medis dengan EHR dan Instalasi rekam medis mengadakan sosialisasi maupun himbauan kepada para dokter IGD

\section{DAFTAR PUSTAKA}

Departemen Kesehatan RI., 1997. Buku Pedoman Pengelolaan Rekam Medis Rumah Sakit di Indonesia. Jakarta: Direktorat Jendral Pelayanan Medik.

Hatta, G., 2011. Pedoman Manajemen Kesehatan di Sarana Pelayanan Kesehatan. Jakarta: Penerbit Universitas Indonesia.

Notoatmodjo, S., 2012. Metodologi Penelitian Kesehatan Edisi Revisi. Jakarta: Rineka Cipta.

Peraturan Menteri Kesehatan Rebuplik Indonesia Nomor.269/MENKES/PER/III/2008 tentang Rekam Medis [Internet]. Jakarta: Departemen 
Kesehatan RI. Tersedia dalam www.depkes. go.id [Diakses 29 Oktober 2013].

Peraturan Menteri Kesehatan Republik Indonesia Nomor 377/MENKES/SK/III/2007 Tentang Standar Profesi Perekam Medis Dan Informasi Kesehatan [internet].Jakarta : Departemen Kesehatan RI. Tersedia dalam www.depkes. go.id [Diakses 1 maret 2014].

Sugiyono., 2010. Metode Penelitian Kuantitatif Kualiatatif dan R\&D. Bandung: Alfabeta.

Peraturan Menteri Kesehatan Nomor 2052/ MENKES/Per/X/2011tentang Izin Praktik Dan Pelaksanaan Praktik Kedokteran
[Internet]. Jakarta : Departemen Kesehatan RI. Tersedia dalam www.depkes.go.id [Diakses 2 maret 2014].

Peraturan Menteri Kesehatan Rebuplik Indonesia Nomor 1438/MENKES/Per/IX/2010 Tentang Standar Pelayanan Kedokteran [Internet]. Jakarta : Departemen Kesehatan RI. Tersedia dalam www.depkes.go.id [Diakses 2 maret 2014].

Peraturan Menteri Kesehatan Nomor 1171 Tahun 2011 Tentang Sistem Informasi Rumah Sakit [Internet]. Jakarta : Departemen Kesehatan RI. Tersedia dalam www.depkes.go.id [Diakses 2 maret 2014]. 